\title{
Práticas formativas de professores dos anos iniciais do ensino fundamental no grupo práticas pedagógicas em rede (ppr)
}

\author{
Training practices of teachersthe elementary \\ school education in the network practice group (ppr)
}

\section{Nilce Lea Lobato Cristovão*}

(iD) https://orcid.org/0000-0001-8262-4826

\section{Edvonete Souza de Alencar ${ }^{* *}$}

(iD) https://orcid.org/0000-0002-5813-8702

\author{
Roseli Araujo Barros ${ }^{* * *}$
}

(iD) http://orcid.org/0000-0001-9767-5546

Doi: 10.17533/udea.unipluri.18.2.07

Cómo citar este artículo:

Cristovão; N. L.L; Alencar, E. S.; y Barros, R. A (2018). Práticas formativas de professores dos anos iniciais do ensino Fundamental no grupo práticas pedagógicas em rede (PPR).

Uni-pluriversidad, 18(2), 102-119. https://doi.org/10.17533/udea.unipluri.18.2.07

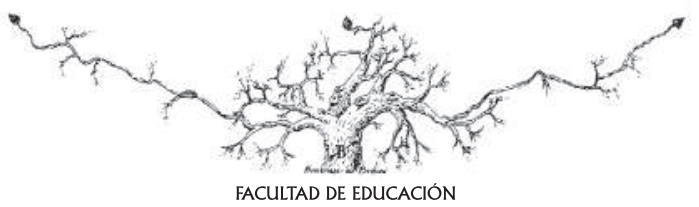

Recibido: 2018-10-07 • Aprobado: 2019-03-24

* $\quad$ Mestre em Políticas Sociais e Licenciada em Pedagogia pela Universidade Cruzeiro do Sul, São Paulo (S.P), Brasil. Atualmente docente do Curso de Licenciatura em Pedagogia e coordena o grupo de estudos Práticas Pedagógicas em Rede. E-mail:nilce.lobato@hotmail.com

** Doutora em Educação Matemática pela PUC-SP. Atualmente é docente na Universidade Federal da Grande Dourados e professora permanente no Mestrado Profissional em Educação Científica e Matemática na Universidade Estadual de Mato Grosso do Sul (MT), Dourados, Brasil. E-mail: edvonete.s.alencar@hotmail.com

*** Doutora e Mestre em Educação em Ciências e Matemáticas pela Universidade Federal do Pará (UFPA), Pará, Brasil e Licenciada em Matemática. Atualmente é docente do Curso de Licenciatura em Matemática na Universidade Estadual de Goiás, Goiás, Brasil. E-mail: roseliaraujo@hotmail.com 


\title{
Resumo
}

Este artigo faz parte de um projeto maior, "Práticas Pedagógicas em Rede (PPR)", desenvolvido com apoio da Universidade Cruzeiro do Sul, com o objetivo de promover a formação de professores e profissionalização do pedagogo baseada na reflexão da/na prática educativa inclusiva. Para o seu desenvolvimento, elencamos a seguinte questão norteadora: Que ações estão sendo desenvolvidas no projeto PPR envolvendo prática educativa inclusiva? As ações propostas no âmbito do PPR, que contempla nossa questão norteadora, são baseadas em projetos individuais e/ou coletivos, designados de Projetos de Aprendizagem Colaborativa (PAC), partindo do interesse do aluno por um tema, seu aprofundamento teórico e reflexão da prática pedagógica. Assim, utilizamos o estudo de caso para descrevermos as práticas formativas colaborativas, desenvolvidas entre agosto de 2017 e junho de 2018, organizadas em distintos contextos formativos, tais como: Formação Inicial; Iniciação à Docência e Formação Continuada. O estudo mostra que as ações no Projeto PPR sugerem possibilidades formativas a diferentes grupos institucionais ao permitir aos envolvidos refletir para/na ação, apontando que se faz necessário propostas de formação de professores e que estas transformações são possíveis.

Palavras chave: Formação de professores, Professor reflexivo, Educação Inclusiva.

\begin{abstract}
This article is part of a larger project, "Pedagogical Practices in Networking (PPR)", developed with the support of the Cruzeiro do Sul University, with the objective of promoting the teacher training and pedagogical professionalization based on the reflection of the inclusive educational practice. For its development, we point out the following guiding question: Are the claims being developed in the PPR project involving inclusive educational practice? The actions proposed in the scope of the PPR, which contemplates our guiding question, are based on individual and / or collective projects, called Collaborative Learning Projects (PAC), based on the student's interest in a topic, their theoretical deepening and reflection on the practice pedagogical Thus, we used the study of case for to describe the collaborative formative practices developed between August 2017 and June 2018, organized in different formative contexts, such as: Initial Formation; Initiation to Teaching and Continuing Education. The study shows that the actions in the PPR Project suggest training possibilities to different institutional groups by allowing those involved to reflect to the action, pointing out that it is necessary to propose teacher training and that these transformations are possible.
\end{abstract}

Key words: Teacher training, Reflective teacher, Inclusive Education. 


\section{Introdução}

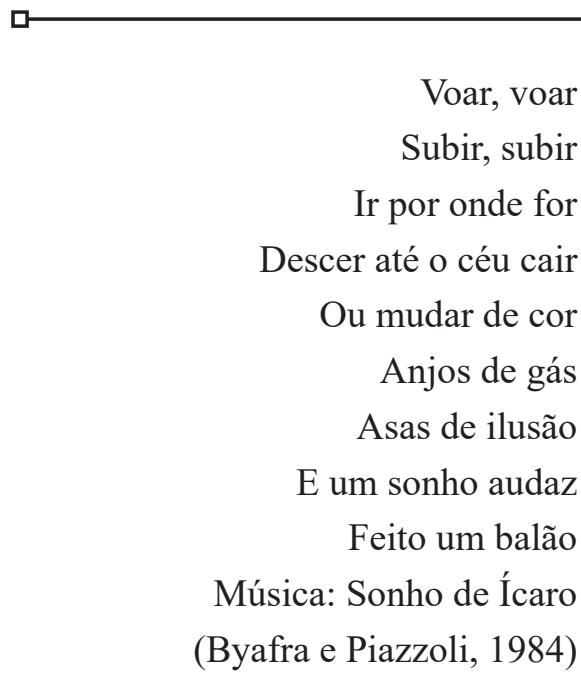

Este artigo inicia suas reflexões com os versos da música Sonho de Ícaro de autoria de Biafra. E nos revela, em forma, de poesia as ações para se alcançar metas e sonhos. Neste contexto, é que apresentamos o projeto "Práticas Pedagógicas em Rede (PPR)", que como a própria música retrata vem alcançando metas e construindo sonhos de uma formação inicial de professores de qualidade. As ações são desenvolvidas com apoio da Universidade Cruzeiro do Sul e possuem um histórico de outros projetos desenvolvidos com outras temáticas, que proporcionaram a consolidação de tais ações formativas.

Entre os anos de 2008 e 2010, houve um estudo investigativo sobre "Histórias de vida de pessoas adultas não alfabetizadas: a memória social da não escolarização", que teve financiamento de bolsas do Programas de Iniciação Científica e Tecnológica/ Conselho Nacional do Desenvolvimento Científico e Técnico (PIBIC/CNPq), realizado por uma das autoras desse artigo, em 2008. Esse estudo desencadeou um projeto sobre "Memória Social em Rede: Histórias e Cultura do Espaço Rural e Urbano do Norte e Sudeste do Brasil". A partir da análise dos dados, em 2009, surgiu a necessidade de desenvolvimento de um terceiro projeto, "Memória social em rede: Histórias e Cultura do Espaço Rural e Urbano do Norte e Sudeste do Brasil", com o objetivo de resgatar a memória, desvelando aspectos culturais e educacionais. Também, no mesmo ano, um quarto projeto surgiu das ações desenvolvidas na investigação dos projetos citados, "Portal colaborativo Programa de Extensão em Educação de Jovens e Adultos (PROEJA)", realizado em rede,com apoio de vários profissionais da área da educação de São Paulo (SP) e Belém do Pará, ainda, de outros colaboradores dos referidos estados.

Este último projeto foi o que proporcionou consolidara investigação atual, visto que já realizávamos parcerias em rede em diferentes estados brasileiros. O projeto PRP possui cadastro no CNPq, no Diretório dos Grupos de Pesquisa Brasil-Lattes, sendo que seu objetivo é de promover a formação de professores e profissionalização do pedagogo baseada na reflexão da/na prática educativa inclusiva. Atualmente, nosso grupo, possui a participação de sete estados, sendo, contando com a colaboração de 21 (vinte e um) alunos.

O projeto iniciou no primeiro semestre de 2017, quando uma das autoras do texto, participou do II Encontro de Práticas da Universidade Cruzeiro do Sul, apresentando algumas práticas formativas desenvolvidas com seus alunos do curso de Pedagogia, na 
referida instituição. No primeiro semestre de 2018, a ideia do projeto PPR tornou-se mais consistente, envolvendo alunos e docentes de outras instituições de Ensino Superior.

Com isso, as ações desenvolvidas no projeto trazem uma pedagogia construída a partir das relações entre teorias e práticas pedagógicas, com registro, análise e reflexão dessas práticas. Inferimos que nossas ações referem-se a uma pedagogia contemporânea, buscando relacionar teoria e prática. Ademais, como o saber e as experiências são linhas tênues e singulares, esperamos que o texto possa contribuir para identificar práticas docentes com autonomia, reflexão, participação, colaboração e contextualização.

Deste modo, organizamos este artigo apresentando a formação do professor num contexto colaborativo e as práticas formativas no âmbito do projeto PPR. Para tanto, delineamos como questão norteadora do artigo: Que ações estão sendo desenvolvidas no projeto $P P R$ envolvendo prática educativa inclusiva? No texto, descrevemos as práticas formativas elaboradas/desenvolvidas no projeto de agosto de 2017 à junho de 2018, divididas em contextos formativos, tais como: Formação Inicial e Formação Continuada.

\section{Encaminhamentos teóricos e metodológicos}

口

Adotamos o estudo de caso para orientar o trabalho, já que estamos interessadas em estudar algo singular. Para Fiorentini e Lorenzato (2012, p. 110), o estudo de caso busca "retratar a realidade de forma profunda e mais complexa possível, enfatizando a interpretação ou a análise do objeto, no contexto em que ele se encontra", mas, não permitindo a manipulação de variáveis e sua generalização. Assim, o estudo de caso pareceu-nos apropriados para nossos anseios.

André (2008), fundamentando-se em Merriam (1988), aponta três características do estudo de caso que consideramos em nosso projeto investigativo, ou seja: (i) Particularidade que focaliza uma situação, um programa, um fenômeno particular. (II) Descrição significa que o produto final de um estudo de caso é a descrição densa do fenômeno em estudo. (iii) Heurística significa que os estudos de caso iluminam a compreensão do leitor sobre o fenômeno estudado. Considerando também estas variáveis e que consideramos adequado esse processo metodológico.

Os dados foram construídos, considerando as ações realizadas no Projeto PPR, de forma particular, para este estudo, nos detemos nos projetos desenvolvidos no âmbito do PPR, que são baseados em projetos individuais e/ou coletivos, designados de Projetos de Aprendizagem Colaborativa (PAC), partindo do interesse do aluno por um tema, seu aprofundamento teórico e reflexão da prática pedagógica.

Ao analisarmos os projetos buscamos apontaros objetivos, metodologiasutilizadas, resultados e aportes teóricos utilizados. A seguir, descrevemos as práticas formativas colaborativas $^{1}$, desenvolvidas de Agosto de 2017 à Junho de 2018, organizadas em distintos contextos formativos, tais como: Formação Inicial; Iniciação à Docência e Formação Continuada. 


\section{A formação de professores: uma revisão de literatura}

Para fundamentarmos nossa investigação buscamos elementos em outras pesquisas que pudessem corroborar com as nossas perspectivas. Assim,a pesquisadora Bernadette Gatti, no ano de 1997, fez um levantamento sobre a formação professores na Educação Básica solicitado pela Comissão de integração Universidade Sistemas de Ensino, do Conselho Nacional de Secretários de Estado da Educação (CONSED). De modo geral, sua investigação revelou aspectos sobre quantos docentes são atuantes, a titulação e o quantitativo de concluintes do magistério e das licenciaturas. É analisada ainda a qualidade formativa dos cursos desde as condições institucionais e das práticas formativas do currículo. Aponta ainda as condições salariais e os atrativos para a inserção na carreira. A autora, neste levantamento realiza sugestões de mudanças necessárias para a formação do professor.

Em um estudo, posterior, encomendado pela Organização das Nações Unidas para Educação, Ciência e Cultura (UNESCO) e pelo Ministério da Educação (MEC), Gatti e Barreto (2009) realizam um levantamento maior a respeito da formação do professor que atua na Educação Básica no Brasil. Menciona acerca do aumento da oferta de cursos nas universidades particulares e públicas, ambas com predomínio de cursos noturno.
Evidencia a presença também de cursos na modalidade à distância. Em ambos os casos as pesquisadoras analisam os currículos e a qualidade do mesmo que depois de uma década ainda apresenta dificuldades.

Em outro levantamento, encomendado pela UNESCO e MEC, realizado por Gatti, Barreto e André (2011) apresentam as políticas públicas de formação de professores. Aludem sobre os novos incentivos dos últimos anos para a formação de professores como: Universidade Aberta do Brasil, o Plano Nacional de Formação de professores da Educação Básica (PARFOR), Programa Pró-Letramento e dentre outros. Em específico, nesta investigação, as autoras alertam para as mudanças que ocorreram no currículo formativo nas últimas décadas e o incentivo por novas metodologias de ensino.

Investigações mais recentes de Ferreira e Alencar (2017), Oliveira e Alencar (2019) apontam a necessidade de uma formação de professores que incentive novas maneiras de ensinar. A primeira investigação traz reflexões sobre os planejamentos dos professores em uma instituição de Educação Infantil e a segunda investigação traz reflexões sobre o uso da Literatura Infantil para o ensino de Matemática em uma perspectiva inclusiva.

\section{Práticas formativas no contexto do Projeto PPR}

As práticas formativas explanadas, neste texto, são fundamentadas nos estudos de André (2016). Esta autora considera que o aluno ao debruçar sobre o próprio trabalho pode entender melhor aquilo que está sendo elaborado, ponderando acerca do que é bom e pode ser aprimorado para obter melhores resultados, construindo, assim, uma aprendizagem eficaz. Do mesmo modo, Schlunzen e Santos (2016), aludem que o aluno estando em um ambiente favorável, que desperte seu interesse, que o desafie, 
motive e explore suas práticas investigativas contribui para refinar suas ideias. Nesse processo, o professor formador tem um papel importante na participação de todas as etapas, sendo mediador do processo reflexivo, relacionada de forma dinâmica com a perspectiva contínua de crescimento do professor

As ações propostas no âmbito do projeto PPR partem de ações do interesse do aluno por um tema e aprofundamento teórico de sua prática pedagógica, com finalidade de uma formação crítico-teórica e torná-los aptos a atuar como profissionais em suas áreas de conhecimento.
Ao propormos a formação inicial e continuada, em que o futuro professor possa refletir de modo crítico, acerca da prática elaborada/desenvolvida. Deste modo, a reflexão torna-se um fator condicionante importante para um enriquecimento pessoal e profissional, atuante na realidade profissional e pode resultar em melhorias em situações iguais e/ou semelhantes no ambiente de trabalho, contribuindo para a ampliação do conhecimento docente.

Para melhor compreensão do leitor, no Quadro a seguir, organizamos os projetos desenvolvidos se já concluídos no âmbito do PPR por: instituição, ano de realização, temática, contexto e autores.

Quadro 1. Organização dos projetos

\begin{tabular}{|c|c|c|c|c|}
\hline INSTITUIÇÃO & ANO & TEMÁTICA & CONTEXTO & AUTORES \\
\hline $\begin{array}{l}\text { Universidade } \\
\text { Cruzeiro do Sul }\end{array}$ & 2017 & $\begin{array}{l}\text { Máquina de } \\
\text { Reciclagem }\end{array}$ & $\begin{array}{l}\text { Formação } \\
\text { inicial }\end{array}$ & Sousa, Danielli Lourenço de \\
\hline $\begin{array}{l}\text { Universidade } \\
\text { Cruzeiro do Sul }\end{array}$ & 2017 & $\begin{array}{l}\text { Atividade } \\
\text { Pedagógica } \\
\text { Inclusiva: } \\
\text { Aprendendo com os } \\
\text { Animais }\end{array}$ & $\begin{array}{l}\text { Formação } \\
\text { inicial }\end{array}$ & $\begin{array}{l}\text { Nogueira, Fernanda Medeiros; Che- } \\
\text { mello, Jaqueline dos Santos; Borges, } \\
\text { Tamires Oliveira Soares }\end{array}$ \\
\hline $\begin{array}{l}\text { Universidade } \\
\text { Cruzeiro do Sul }\end{array}$ & 2018 & $\begin{array}{l}\text { Matemática } \\
\text { Interdisciplinar na } \\
\text { Educação Inclusiva }\end{array}$ & $\begin{array}{l}\text { Formação } \\
\text { inicial }\end{array}$ & $\begin{array}{l}\text { Santos, Érica Gomes dos; Souza, } \\
\text { Alana Thays da Silva; Andrade, } \\
\text { Andréia Maria de; }\end{array}$ \\
\hline $\begin{array}{l}\text { Universidade } \\
\text { Cruzeiro do Sul }\end{array}$ & 2018 & $\begin{array}{l}\text { Mapa Mental: Uma } \\
\text { abordagem possível } \\
\text { para o Ensino } \\
\text { da Matemática } \\
\text { Inclusiva. }\end{array}$ & $\begin{array}{l}\text { Formação } \\
\text { inicial }\end{array}$ & $\begin{array}{l}\text { Dolival, Ronaldo Gobbis; } \\
\text { Silva, Maristela da Silva; }\end{array}$ \\
\hline $\begin{array}{l}\text { Universidade } \\
\text { Cruzeiro do Sul }\end{array}$ & 2017 & $\begin{array}{l}\text { Coque Tok: } \\
\text { Brinquedo, } \\
\text { Brincadeira e } \\
\text { Aprendizagem }\end{array}$ & $\begin{array}{l}\text { Formação } \\
\text { inicial }\end{array}$ & $\begin{array}{l}\text { Custódio, Jefferson de S.; Jesus, Je- } \\
\text { ziel Pereira de; Ferreira, Karolyn; } \\
\text { Amaral, Canuto, Roselane; }\end{array}$ \\
\hline $\begin{array}{l}\text { Universidade } \\
\text { Cruzeiro do Sul }\end{array}$ & 2018 & $\begin{array}{l}\text { Alfabetizando de } \\
\text { Maneira Lúdica e } \\
\text { Criativa }\end{array}$ & $\begin{array}{l}\text { Formação } \\
\text { inicial }\end{array}$ & Macedo, Gustavo Gabriel \\
\hline
\end{tabular}




\begin{tabular}{|c|c|c|c|c|}
\hline INSTITUIÇÃO & $A N O$ & TEMÁTICA & CONTEXTO & AUTORES \\
\hline $\begin{array}{l}\text { Universidade } \\
\text { Cruzeiro do Sul }\end{array}$ & 2018 & $\begin{array}{l}\text { Vamos aprender } \\
\text { brincando juntos? }\end{array}$ & $\begin{array}{l}\text { Formação } \\
\text { inicial }\end{array}$ & $\begin{array}{l}\text { Bezerra, Ariadne Alves; Cambraia, } \\
\text { Eliete da Silva; Verissimo, Jac- } \\
\text { queline; Souza, Alana Thays da } \\
\text { Silva;Carvalho, Érica Gomes de; } \\
\text { Mondenini, Jaqueline; Cardoso, Bár- } \\
\text { bara Cristina Silva; Santos, Ivanise } \\
\text { Elias da Silva; Guimarães, Rosana } \\
\text { Barros;Sousa, Danielli Lourenço de; } \\
\text { Campos, Elaine Jordão de; Coca, } \\
\text { Giselle Mariana; Almeida, Renata } \\
\text { de;Custódio, Jefferson; Nascimento, } \\
\text { Cristiano da Silva }\end{array}$ \\
\hline $\begin{array}{l}\text { Universidade } \\
\text { Cruzeiro do Sul }\end{array}$ & 2018 & $\begin{array}{l}\text { Projeto } \\
\text { Interdisciplinar } \\
\text { Horta Comunitária } \\
\text { Inclusiva }\end{array}$ & $\begin{array}{l}\text { Formação } \\
\text { continuada }\end{array}$ & Oliveira, Fabiana Nunes de \\
\hline $\begin{array}{l}\text { Universidade } \\
\text { Estadual de } \\
\text { Goiás (UEG) }\end{array}$ & 2018 & $\begin{array}{l}\text { Uma proposta de } \\
\text { sequência didática } \\
\text { para o ensino de } \\
\text { Matemática nos anos } \\
\text { iniciais do Ensino } \\
\text { Fundamental }\end{array}$ & $\begin{array}{l}\text { Formação } \\
\text { continuada }\end{array}$ & Silva, Thayssa Pereira da \\
\hline
\end{tabular}

Fonte: Elaborado pelas autoras com base nos projetos.

O projeto, Máquina de Reciclagem, teve os seguintes objetivos: Identificar através das cores o local correto para descarte de certos lixos; desenvolver habilidades cognitivas e incentivar a compreensão sobre a área de conhecimento. A metodologia utilizada foi qualitativa, a partir de observação de aulas em uma Escola Pública nos Anos Iniciais do Ensino Fundamental (EF) na cidade de São Paulo (SP).

Assim, por meio da atividade com a máquina de reciclagem, buscaram despertar o interesse dos alunos para o tema, relacionando-o a diferentes tipos de lixos utilizados em reciclagem. A partir do que foi observado, em sala de aula, para dar acesso a todos os alunos a atividade, criaram uma mesa ajustável e inclinada com teclado, cores e luzes para estimular uma aluna com deficiência motora a participar da atividade. Iniciou com um tema abordado no livro dos alunos, em seguida, a prática com a máquina de reciclagem. Aponta-se como resultados a promoção da autonomia do aluno com deficiência, a independência, a participação de todos independente da especificidade. Permitiram, ainda, que acadêmicos do curso de Pedagogia pudessem vivenciar as ações interdisciplinares de construção de materiais para o ensino inclusivo.

Imagem 1. Mesa ajustável e inclinada

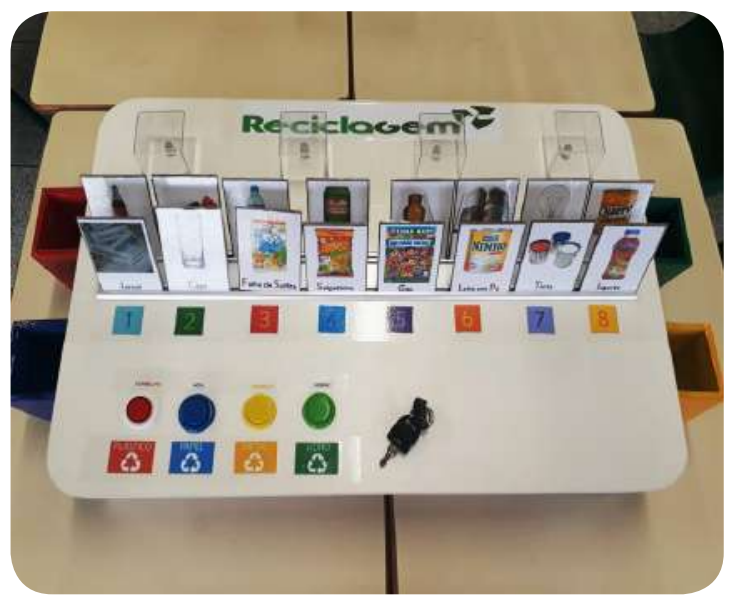

Fonte: Arquivo pessoal dos autores do projeto 
Outro projeto, Atividade Pedagógica Inclusiva: aprendendo com os animais, com o objetivo de desenvolver habilidades cognitivas e o raciocínio lógico, desenvolver a linguagem e a autonomia. A metodologia utilizada foi qualitativa, que a partir da observação no Estágio nos Anos Iniciais do EF, elaborou-se um material pedagógico intitulado: "Aprendendo com os animais". O propósito do material foi de incentivar o aluno com deficiência a aprender a ler e escrever de forma lúdica criando condições da assimilação de modo divertido. Participaram da atividade 28 (vinte oito) crianças, entre sete e oito anos, do segundo anos do EF de uma instituição Pública e Estadual, em SP.

Em seu desenvolvimento, os autores perceberam que as dificuldades no método educativo do aluno com deficiência têm sido evidenciadas nas escolas regulares, como por exemplo, leitura e escrita como uma forma de comunicação expressa em palavras e transmitida entre as sociedades. Ademais, buscou-se incluir e melhorar a compreensão dos alunos na construção das palavras, visando à formação de frases, resultando em elaboração de texto.

creditando num contexto lúdico contínuo e motivador, para o desenvolvimento da consciência fonológica e do processo de compreensão dos alunos com ou sem deficiência, foi desenvolvido um jogo pedagógico, envolvendo conhecimentos alfabéticos com os alunos com deficiência cognitiva. Nele, é necessário que o aluno tenha percepção, autonomia e habilidade para girar o cubo para compreender o som da sílaba do nome do animal.

Os autores concluíram que a atividade pode proporcionar acesso a todos os alunos, desenvolvendo concentração, percepção, raciocínio lógico, autonomia e a socialização. Os alunos compreenderam as letras, a fonética do som das letras e a consciência fonológica.

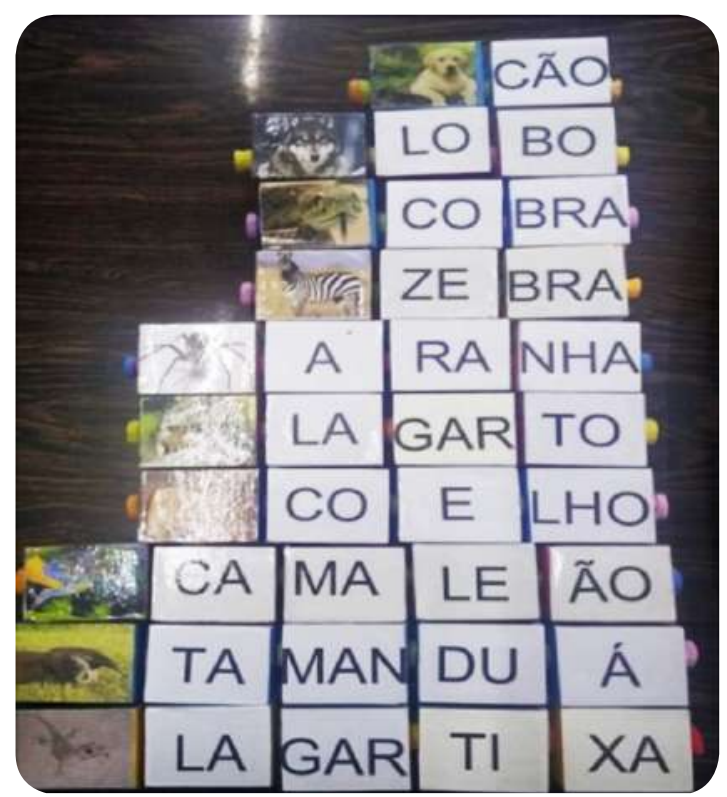

Fonte: Arquivo pessoal dos autores do projeto.

O projeto, Matemática Interdisciplinar na Educação Inclusiva, teve como objetivo relacionar as imagens com as letras e algarismos, identificando quantidades. Para tanto, utilizou-se de uma metodologia do tipo qualitativa, a partir questões não estruturadas aplicadas a professora dos Anos Iniciais do EF sobre suas dificuldades diárias com os alunos. Também elaboraram um material, buscando a aprendizagem de todos os alunos incluindo Matemática e língua portuguesa, a partir de algarismos, imagens, letras soltas, palavras fechada, escrita e leitura.

Os alunos não apresentaram dificuldades no desenvolvimento da atividade, aqueles com limitações, tiveram um pouco de resistência para iniciar, concluíram a atividade em um período maior de tempo. A outra aluna não realizou, sendo necessários 
outros recursos, como tinta e outros materiais por proporcionar um acesso mais eficiente à atividade. As adaptações fazem com que os alunos aprendam e atinjam o maior nível de aprendizagem.

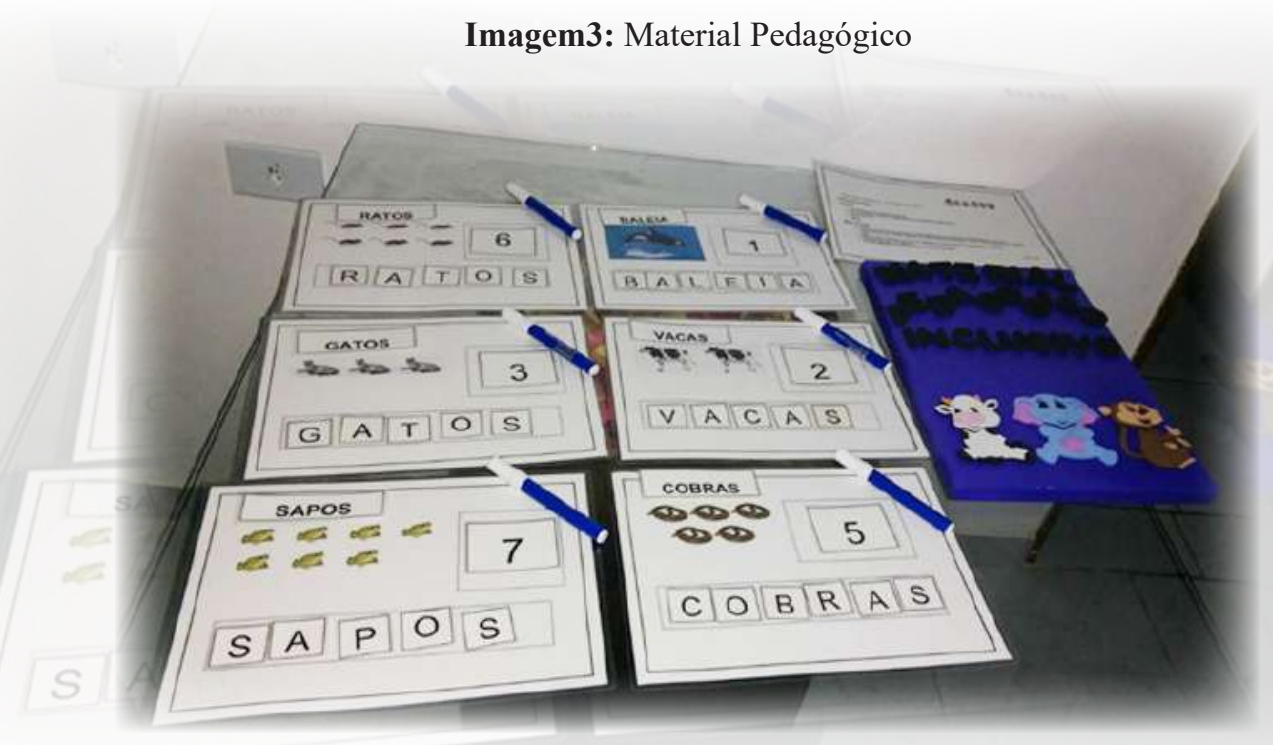

Fonte: Elaborado pelos autores do projeto.

O projeto, Mapa Mental: Uma abordagem possivel para o Ensino da Matemática Inclusiva teve como objetivo desenvolver ferramentas que facilitem o reconhecimento das habilidades da criança com deficiência intelectual. Nesse contexto, o papel do professor é de possibilitar aos alunos trocas de conhecimentos no meio em que estão inseridos, valorizando sua autonomia e independência, além disso, estimulá-las para que participem dos momentos de compartilhamento e trocas dos conhecimentos, sociais, afetivos e cognitivos. Desta forma, o professor assume o papel de mediador entre a criança e o mundo.

A metodologia partiu dos princípios dos mapas mentais, entende-os como ferramentas de pensamento que permitem refletir, exteriormente, o que se passa na mente. Por meio de imagens, foram mostradas aos alunos de uma Escola Pública Estadual, em SP, as etapas da construção do sistema que utilizamos para uma Prática
Pedagógica Inclusiva Universal, a partir da elaboração de temas e palavras-chaves, material e figuras. Ao desenhar o mapa mental que, por sua vez, foi mantido preso por fitas adesivas comuns as palavras e figuras.

As expectativas em relação ao projeto foram satisfatórias, acreditando que as dificuldades pedagógicas de aprendizagem podem ser amenizadas. No desenvolvimento da prática pedagógica, três alunos com deficiência intelectual conseguiram realizar a atividade. Os alunos construíram, participaram do conhecimento junto ao material pedagógico, com comportamentos e a apreensão do conhecimento. Os autores acreditam que a aprendizagem nem sempre acontece desse modo, mas o controle das situações inusitadas, que ocorrem por comportamentos da indisciplina, por dificuldade de aprendizagem, pode ser contornado pelo professor sem muitas intercorrências. 
Imagem 4. Material pedagógico

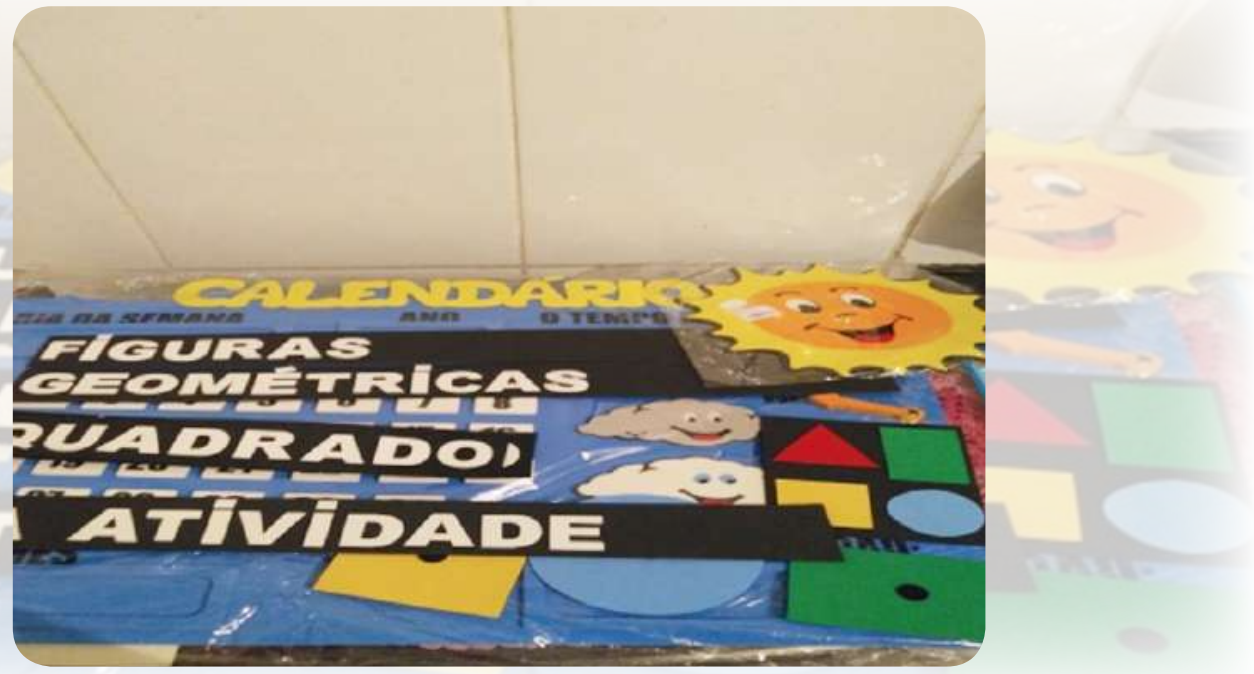

Fonte: Arquivo pessoal dos autores.

Já o projeto, Coque Tok: Brinquedo, Brincadeira e Aprendizagem, com o objetivo de aumentar o repertório de cores, estimular diversas áreas sensoriais de forma lúdica e, assim, instigar a audição e a visão. O nome, Coque-Tok, foi escolhido pelo formato lúdico que representa um coqueiro e pela questão sensorial, uma vez que é um brinquedo tátil, que ativa o desenvolvimento cognitivo de uma criança no âmbito educacional. Ademais, pode ser trabalhado na Educação Inclusiva, com crianças com deficiências visuais e intelectuais, bem como o Transtorno do Espectro Autista (TEA).

Para a Elaboração de um coqueiro sensorial, uma série de materiais pedagógicos foi anexada ao longo do tronco do coqueiro para que a criança possa explorá-los de maneira fácil e voluntária. A atividade visa estimular os movimentos da criança, a fim de que sejam trabalhados coordenação motora, lateralidade e equilíbrio. Recomendam que o professor que aplique a atividade direcionando o nome de cada item dos materiais para que o aluno possa se apropriar de cada objeto.

O desenvolvimento do projeto possibilitou uma análise de como um brinquedo interativo pode auxiliar $\mathrm{o}$ professor a melhorar a compreensão dos alunos. Além disso, contribuiu, de modo geral, na evolução corporal e sensorial. A Psicomotricidade é importância para o desenvolvimento humano, o Coque-Tok forneceu ao professor e alunos um ambiente enriquecedor, motivador, além de divertido.

Imagem 5. Coqueiro sensorial

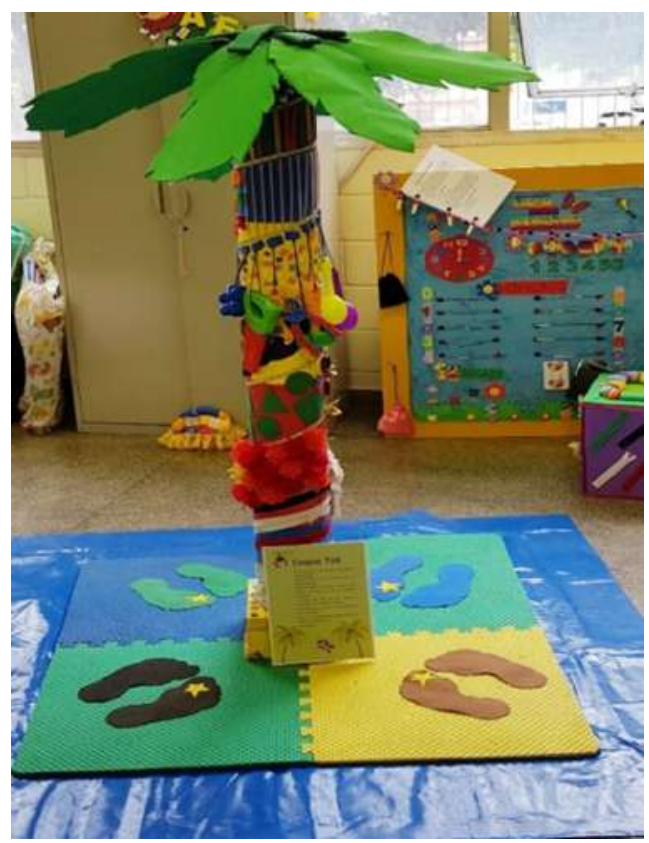

Fonte: Acervo pessoal dos autores 
$\mathrm{O}$ projeto, Alfabetizando de Maneira Lúdica e Criativa, teve como objetivo: proporcionar autonomia para resolução de problemas, contribuir para $\mathrm{o}$ desenvolvimento do ensino e aprendizagem. No período do Estágio, na Iniciação à Docência, com o intuito de despertar o interesse pela pesquisa, foram realizadas algumas pesquisas, por meio da criação e estratégias para identificar o nível de assimilação do aluno. Para tanto, utilizouse da sondagem, partindo do interesse dos alunos por brinquedos e giz de lousa. As palavras selecionadas foram: patinete, boneca, bola e giz, informando aos alunos somente a escreverem as palavras e que, não era uma avaliação. Em seguida, os alunos escreveram as palavras ditadas em uma folha em branco. Após o resultado, foi elaborada atividade com intervenções de acordo com a dificuldade de cada aluno.

Os alunos tiveram um avanço significativo após as intervenções contextualizadas, apresentando mais autonomia para escrever e não apenas copiarem o conteúdo da lousa. Também associaram o ato de ler e escrever de modo contínuo, dessa forma, os alunos praticou a leitura diariamente.

Imagem 6. Material pedagógico

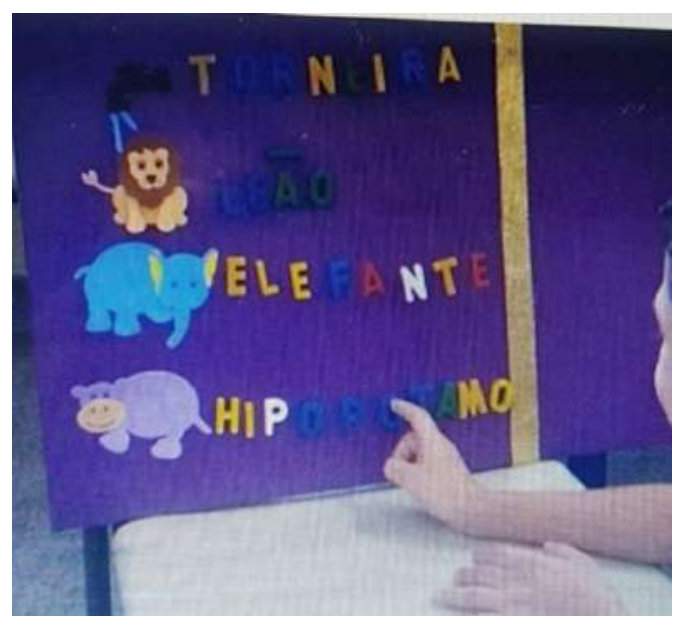

Fonte: Acervo pessoal dos autores
Já o projeto Vamos aprender brincando juntos?, com o objetivo de incluir os acadêmicos do curso de Pedagogia nas atividades, incentivando-os a participar do Estágio em Iniciação à Docência, a partir de atividades lúdicas, assim, contribuindo com a Formação Docente.

No desenvolvimento foi aplicado uma sequência de atividades elaboradas e relacionadas com a proposta curricular da escola, em que se executaria o projeto, buscando a participação dos alunos participem das atividades de forma lúdica. Cada grupo de licenciandos elaborou um Projeto de Intervenção, a partir do material pedagógico criado e desenvolvido na Disciplina de Prática de Ensino, Corpo Movimento e Psicomotricidade para dois grupos de 15 (quinze) alunos do segundo ano, foram duas horas por semana de intervenções, totalizando dezoito horas. Os licenciandos perceberam que o interesse pelo lúdico é algo motivador, já que os alunos foram participativos, criativos, compreenderam a proposta.

Imagem 7: Atividades elaboradas

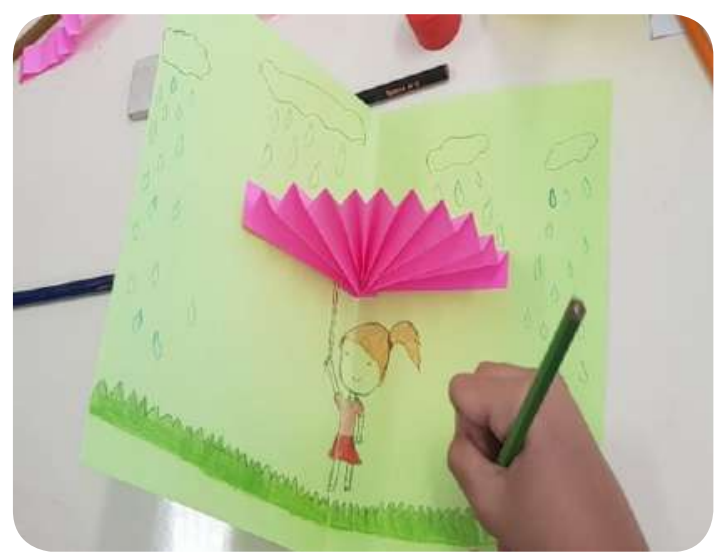

Fonte: Acervo das autoras

Já o Projeto Interdisciplinar Horta Comunitária Inclusiva faz parte da formação continuada, sendo que uma aluna egressa do curso de Pedagogia é responsável pela ação. 
Partindo do seguinte questionamento: Será que as crianças se interessariam por uma horta na escola? Uma horta colaborativa na escola contribui para uma alimentação saudável das crianças? Para respondê-los, elaboraram os seguintes objetivos: refletir sobre a importância da reutilização do pneu; compreender sobre a alimentação saudável; conhecer os diversos tipos de solo, alimentação e como preparar o plantio e; socializar o aluno com o meio ambiente, garantir o ensino e aprendizagem de saúde e bem-estar. A faixa etária dos alunos participantes do projeto são 6 (seis) a 10 (dez) anos apresentando especificidades, diferença na idade, comportamento social, cognitivo, aprendizagem e conhecimento prévio sobre o tema. Os alunos participam desde a preparação da terra, cuidados com o plantio até a colheita, em paralelo foram elaboradas atividades pertinentes ao tema.

A partir do projeto, os alunos vêm apresentando desempenho, criatividade, coordenação motora, socialização, interesse ao tema, dispostos a novos conhecimentos, interesse em pesquisas e, assim, estão criando habilidades e atitudes autônomas. $\mathrm{O}$ projeto iniciou em fevereiro de 2018 e, ainda, encontra-se em fase de andamento.

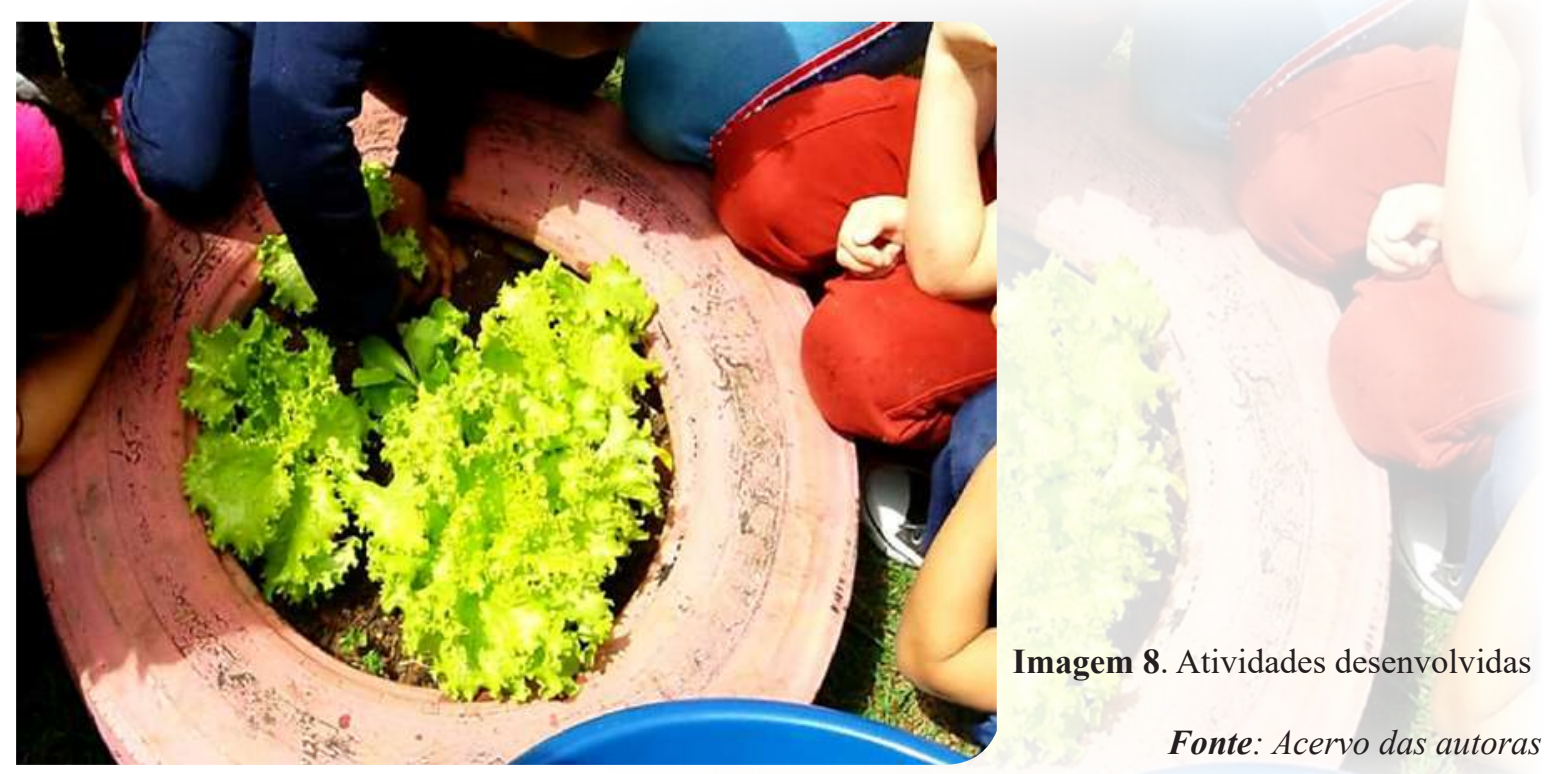

O projeto, Uma proposta de sequência didática para o ensino de Matemática nos anos iniciais do Ensino Fundamental, realizado com o apoio da Universidade Estadual de Goiás (UEG) foi uma experiência realizada com alunos do segundo ano do EF. Nela, desenvolveram uma sequência didática para o ensino de Matemática, a partir da literatura infantil, inserindo noções de contagem, correspondência uma a uma, adição e subtração. A metodologia utilizada foi à pesquisa participante, que conforme
Brandão (1987) consiste na observação participante, sem que, contudo, tivesse se tornado, ela mesma, politicamente participante. Sob a influência do marxismo, a observação participante busca conhecer para explicar o outro se transmuta em pesquisa participante, procurando, então, compreender para servir. Convivência e compromisso articulam-se para dar sentido a uma prática científica que participa do trabalho político das classes populares. 
Utilizaram o livro "Meus porquinhos" de Audrey Wood e Don Wood. Partindo da leitura da obra, propondo aos alunos, algumas questões norteadoras: Quais porquinhos vão aparecer agora? Quais serão os próximos porquinhos a aparecer? A bailarina aparece na mão esquerda ou direita? O que os porquinhos representam? Por que o autor utilizou porcos como personagens principais? Quais são os adjetivos que os dedos recebem? Após a discussão, foi sugerido, aos mesmos, um desafio chamado Vamos dar nome aos nossos dedinhos? Cada aluno desenhou suas mãos, diferenciando a mão esquerda da mão direita e, por meio da música "Os dedinhos", os alunos aprenderem o nome de cada um dos dedos, fazendo algumas anotações. Em seguida, eles fizeram a transcrição da história utilizando sua criatividade e imaginação, para a ilustração de um livro. E, por fim, foi sugerido algumas atividades envolvendo contagem, correspondência uma a uma, adição e subtração.

Assim, no desenvolvimento das atividades, foi observado que houve uma socialização dos alunos no ambiente escolar, levando em consideração as particularidades de cada aluno, despertando o interesse dos mesmos no mundo da leitura e escrita.

Imagem 9. Capa do livro produzido pelos alunos

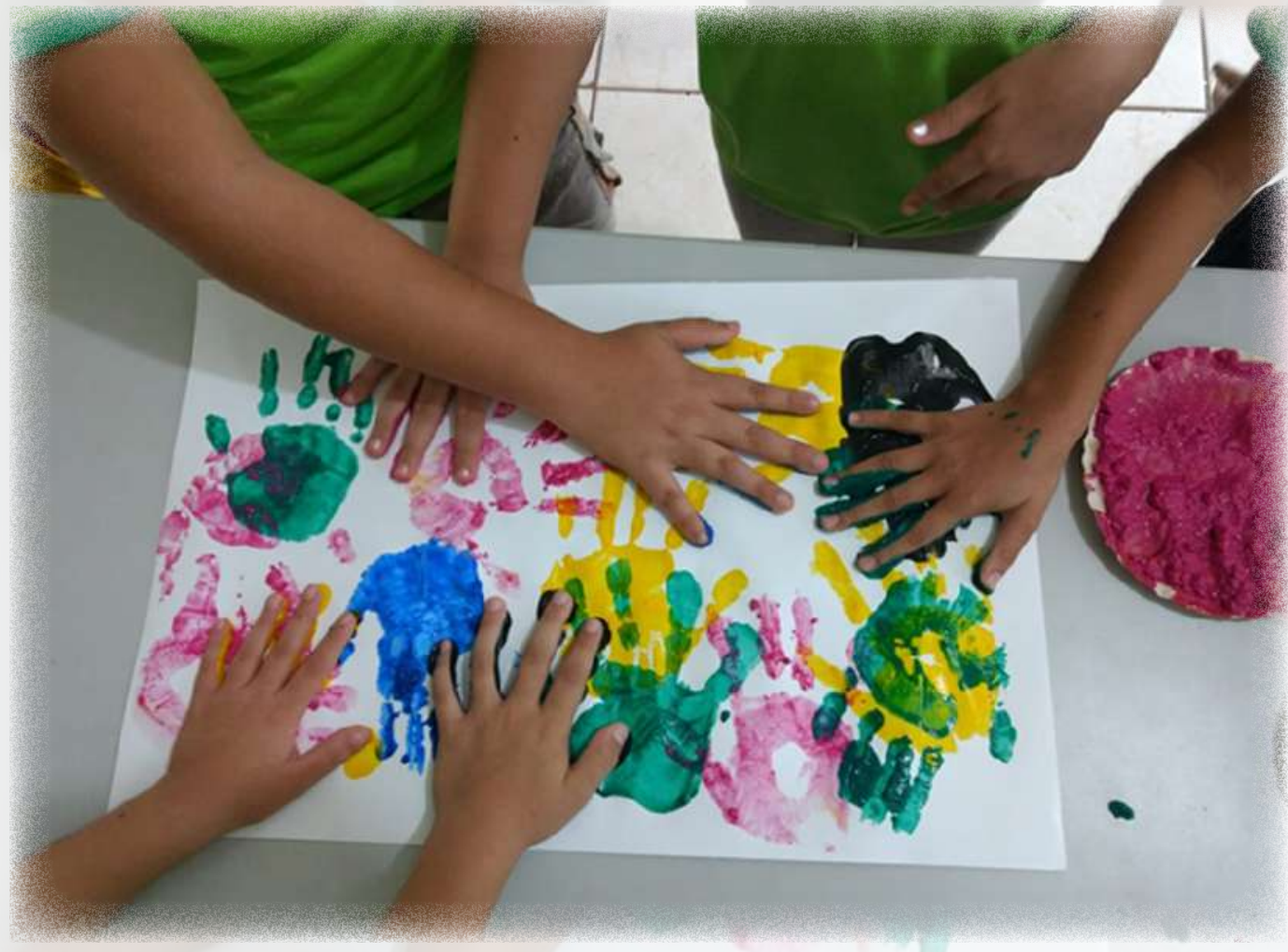

Fonte: Acerco das autoras do projeto.

Para uma melhor compreender as bases epistemológicas dos projetos analisadas, elaboramos um quadro, para que possamos ter uma ideia mais ampla dos teóricos utilizados em cada trabalho. 
Quadro2. Bases epistemológicas dos trabalhos.

\begin{tabular}{|c|c|}
\hline Projeto & Tendência, referencial teórico e ano \\
\hline Máquina de reciclagem & $\begin{array}{ll}\text { - } & \text { Elaboração de projeto: Gil (2002) } \\
\text { - } & \text { Inclusão: Mantoan (2006); Brasil (1997). }\end{array}$ \\
\hline $\begin{array}{l}\text { Atividade Pedagógica } \\
\text { Inclusiva: Aprendendo } \\
\text { com os Animais }\end{array}$ & $\begin{array}{ll}\text { - } & \text { Elaboração de projeto: Gil (2002) } \\
\text { - } & \text { Psicogênese da Língua Escrita: Ferreiro Teberosky (1999) e } \\
\text { - } & \text { Linguagem e pensamento: Vigostsky (1989). }\end{array}$ \\
\hline $\begin{array}{l}\text { Coque Tok: Brinquedo, } \\
\text { Brincadeira e } \\
\text { Aprendizagem }\end{array}$ & $\begin{array}{l}\text { - } \quad \text { Elaboração de projeto: Gil (2002) } \\
\text { - } \quad \text { Aprendizagem da criança:Fernandes (2008) } \\
\text { - } \quad \text { Autismo: Schmidt (2013) }\end{array}$ \\
\hline $\begin{array}{l}\text { Mapa Mental: Uma } \\
\text { abordagem possível para } \\
\text { o Ensino da Matemática } \\
\text { Inclusiva }\end{array}$ & $\begin{array}{l}\text { - } \quad \text { Elaboração de projeto: Gil (2002) } \\
\text { - } \quad \text { Comunicação Política: Semetko, Scammell (2012) } \\
\text { - } \quad \text { Educação comparada: Marcondes (2005). }\end{array}$ \\
\hline $\begin{array}{l}\text { Alfabetizando de Maneira } \\
\text { Lúdica e Criativa }\end{array}$ & $\begin{array}{l}\text { - } \quad \text { Educação Infantil: Ostetto (2000); } \\
\text { - } \quad \text { Alfabetização: Fernandes (2010). }\end{array}$ \\
\hline $\begin{array}{l}\text { Vamos aprender brincando } \\
\text { juntos? }\end{array}$ & $\begin{array}{l}\text { - } \quad \text { Brinquedoteca: Gimenes (2011); } \\
\text { - Pesquisa colaborativa: Pimenta, Garrido e Moura (2000). }\end{array}$ \\
\hline $\begin{array}{l}\text { Projeto Interdisciplinar } \\
\text { Horta Comunitária } \\
\text { Inclusiva }\end{array}$ & $\begin{array}{ll}\text { - } & \text { Pesquisa qualitativa: Minayo (2009) } \\
\text { - } & \text { Saberes docentes: Freire (2002) } \\
\text { - } & \text { Inclusão: Omote (2004). }\end{array}$ \\
\hline $\begin{array}{l}\text { Matemática } \\
\text { Interdisciplinar na } \\
\text { Educação Inclusiva }\end{array}$ & $\begin{array}{ll}\text { - } & \text { Elaboração de projeto: Gil (2002) } \\
\text { - } & \text { Linguagem e pensamento: Vigostsky (1989) } \\
\text { - } & \text { Literatura e alfabetização: Saraiva (2001) } \\
\text { - } & \text { Inclusão: Mantoan (2006) }\end{array}$ \\
\hline $\begin{array}{l}\text { Uma proposta de } \\
\text { sequência didática para o } \\
\text { ensino de Matemática nos } \\
\text { anos iniciais do Ensino } \\
\text { Fundamental }\end{array}$ & $\begin{array}{ll}\text { - } & \text { Educação infantil e Matemática: Lorenzato (2006); Smole (2006); } \\
\text { - } & \text { Literatura e alfabetização: Saraiva (2001) } \\
\text { - } & \text { Pesquisa participante: Brandão (1987) }\end{array}$ \\
\hline
\end{tabular}

Fonte: Elaborado pelas autoras com base nos projetos analisadas.

Os trabalhos analisados apontam experiências vivenciadas trouxeram embasamentos teóricos diversificados no conhecimentos e descobertas, possibilitando campo da Educação Infantil, da Educação uma reestruturação das práticas e modos de Inclusiva e da Educação Matemática ser/estar na profissão docente. Estruturar as com enfoque nos anos iniciais, pesquisa práticas formativas, implica em pensar que a participante, Alfabetização, Pesquisa colaborativa, Brinquedoteca, etc. As futuro professor não se finda na conclusão de 
uma graduação, mas se prolonga por toda a vida. Tais mudanças percebidas nas práticas pedagógicas dos envolvidos nos projetos coadunam com as perspectivas de práticas formativas colaborativas. Nesse sentido, Nascimento e Cristovão (2018), afirmam que as práticas pedagógicas contribuem para que os alunos conseguissem refletir, criar e analisar materiais procurando novas formas de aplicar ou modificá-los.

Concordamos com Schlunzen e Santos (2016), ao afirmarem que é basilar que o professor construa sua maneira própria de ensinar, sem seguir modelos dos outros ou métodos dos outros. Deve estar claro, para ele, que os alunos saibam estabelecer as relações e trabalhar com as inúmeras informações que estão em todos os lugares. Esse movimento é percebido nos projetos, contribuindo para buscar um aprendizado e desenvolver em si atitudes interdisciplinares.

Portanto, a formação assume um papel que supera o ensino pedagógico, científico e didático e se transforma e possibilita a criação de espaços de participação, reflexão para que os alunos possam aprender e adaptar para poder viver com a mudança e incerteza. Com isso, o processo de formação é reflexivo e experiencial repleto de descobertas, contribuindo para buscar um aprendizado e desenvolver em si atitudes interdisciplinares, assim como cita Imbernón (2011).

\section{Considerações finais}

Este artigo apresentou as ações desenvolvidas no Projeto PPR, entre agosto de 2017 e junho de 2018, bem como, os projetos realizados em distintos contextos formativos (Formação Inicial; Iniciação à Docência; Formação Continuada). Parafraseando Byafra (1984), este projeto é um sonho audaz, que vem sendo elaborado/ implementado por distintas parcerias institucionais voltadas para a melhoria da formação inicial do pedagogo, baseada na ação-reflexão da/na prática educativa inclusiva. Os trabalhos evidenciam bases epistemológicas diversificadas no campo da Educação Infantil, Educação Inclusiva, Educação Matemática com foco nos anos iniciais, pesquisa participante, Alfabetização, Pesquisa colaborativa, Brinquedoteca, etc.

As experiências vivenciadas, no PPR, trouxeram conhecimentos e descobertas, permitindo uma reestruturação das práticas e modos de ser/estar na profissão docente. As práticas pedagógicas contribuíram para que os sujeitos em formação refletissem, criassem e analisem os materiais pedagógicos utilizados, buscando novos modos de aplicá-los e/ou modificá-los. Tais mudanças percebidas nas práticas pedagógicas dos envolvidos nos projetos coadunam com as perspectivas de práticas formativas colaborativas, como aquelas que desencadeiam modos de aprender a ensinar a profissão.

As ações desenvolvidas, no PPR, dão sugestões de possibilidades formativas as demais grupos institucionais, revelando que é preciso implementar atividades na formação de professores baseadas na pesquisa e que estas transformações podem ser possíveis. Neste sentido, se faz necessário possibilitar uma formação aos nossos alunos - pedagogos: "voar, voar...subir...subir" e alcançar sonhos e serem protagonistas de seu processo formativo, buscando promover um ensino e aprendizagem com qualidade. 


\section{Anotações}

1. Neste texto, práticas formativas foram adotadas como meio para melhor conhecimento dos projetos desenvolvidos no âmbito do PPR. Numa acepção imediata, práticas formativas é o modo como um currículo de um curso (inicial ou continuado) é desenvolvido, ainda, refere-se às maneiras bem identificáveis de ensinar, mas também à qualidade das relações estabelecidas entre professor e alunos (GUIMARÃES, 2004). Ademais, entendemos por práticas formativas colaborativas como sendo aquelas práticas oriundas da formação (inicial e continuada) do sujeito, de modo individual e/ou em colaboração, desencadeando modos de aprender a ensinar a profissão.

\section{REFERÊNCIAS BIBLIOGRÁFICAS}

André, Marli. (2016). Práticas Inovadoras na Formação de Professores. São Paulo, Brasil. 1 Ed. Papirus.

André, Marli. (2008). Estudo de caso em pesquisa e avaliação educacional. Brasília, Brasil: Liber livro.

Bezerra, A.A., Cambraia, E.da S., Veríssimo, J., Souza, A.R. da Silva, Carvalho, É.G. de, M. Cristovão, N.L.L (2018). Vamos aprender brincando juntos? Universidade Cruzeiro do Sul. São Paulo, Brasil, SP.

Brandão, C. R. (1987). Repensando a pesquisa participante. $3^{\circ}$ Ed. São Paulo, Brasil: Editora Brasiliense.

Brasil. (1997) Secretaria de Educação Fundamental. Parâmetros Curriculares Nacionais: Matemática / Secretaria de Educação Fundamental. Brasília, Brasil: MEC/SEF.

Brasil, (2007) Ministério da Educação. Ensino Fundamental de nove anos: orientações para a inclusão da criança de seis anos de idade. Brasília, Brasil, DF: MEC.

Byafra, M.P.R., Piazzoli, C.R. (1984). Sonho de Ícaro Interpretes:Byafra.. Gravadora Sony music. Rio de Janeiro, Brasil.

Cristovão, N.L.L., Nascimento, R.P. Alencar, E.S; Cambraia, E. da S.; Silva, D. M. (2018). Práticas formativas e recursos metodológicos inclusivos. Anais do XIX Encontro Nacional de Didática e Práticas de Ensino - XIX ENDIPE, Universidade Federal da Bahia, Salvador, Bahia.

Camargo, P. E. (2017). Inclusão Social, educação inclusiva e educação especial: enlaces e desenlaces. VI 23 UNESP, Bauru. São Paulo, Brasil.

Custódio, J. de S., Jesus, J. P.; Amaral, K.F., Canuto, R., Ferreira, K., Cristovão, N.L.L. (2018). Coque Tok: Brinquedo, brincadeira e aprendizagem. Universidade Cruzeiro do Sul. São Paulo, Brasil, S.P.

Dolival, G. R.; Silva M., Cristovão, N.L.L.; Nascimento, R. P. (2018). Mapa Mental: Uma abordagem possível para o ensino de Matemática inclusiva. Revista de Educação Horizontes. UFGD, Mato Grosso do Sul, 2018. 
Franco, M.A.S.(2005). A Pedagogia da pesquisa ação. In: Encontro Nacional de Didática e Prática de Ensino, 12, 2005, Curitiba. Anais. Curitiba: Endipe.

Ferreiro, E, Teberosky, A. (1999). Psicogênese da Língua Escrita. Porto Alegre, Brasil: Artmed.

Fernandes, A.P. (2008). A importância do movimento na aprendizagem e no desenvolvimento da criança. PUC de São Pulo. São Paulo, Brasil.

Fernandes, M. (2010). Os segredos da alfabetização. São Paulo, 2.ed. Cortez.

Ferreira, L. G. Alencar E. S. (2017) Juegos para enseñar matemáticas en la planificación para los profesores de educación infantil. RECME-Revista Colombiana de Matemática Educativa 2 (1), $30-38$

Fiorentini, D., Lorenzato, S.. (2012). Investigação em Educação Matemática: percursos teóricos e metodológicos. Campinas, Brasil: Autores Associados.

Freire, P. (2002). Pedagogia da autonomia: Saberes Necessários à Prática Educativa. São Paulo, Brasil: Impresso Brasil.

Gatti, B. A. e Barreto, E. S. S. (coord.) (2009). Professores do Brasil: impasses e desafios. Brasília, Brasil: UNESCO.

Gatti, B. A. (1997). Formação de professores e carreira: problemas e movimentos de renovação. Campinas: Autores Associados.

Gatti, B. A., Barreto, E. S. S. e André, M. A. D. (2011). As Políticas Docentes no Brasil - um estado da arte. Brasília, Brasil: UNESCO.

GIL, Antonio Carlos. (2002). Como elaborar projetos de pesquisa. São Paulo, Brasil, Editora Atlas, 2002.

Gimenes, B. P. (2011). Brinquedoteca: Manual em educação e saúde; Sirlândia Reis de Oliveira Teixeira. São Paulo, Brasil: Cortez.

Goulart, I.B. (2009). Piaget: experiências básicas para utilização pelo professor. Petrópolis, Rio de Janeiro, Brasil: Vozes.

Guimarães, Valter Soares (2004). Formação de professores: saberes, identidade e profissão. Campinas, São Paulo, Brasil: Papirus.

Imbernón, Francisco. (2011) Formação docente e profissional: formar-se para mudança e a incerteza. São Paulo, Brasil: Cortez.

Lorenzato, S. (2006). Educação infantil e percepção matemática. Campinas: Autores Associados.

Macedo, G.G., Cristovão, N.L.L. (2018). Alfabetizando de Maneira Lúdica e criativa. Universidade Cruzeiro do Sul. São Paulo, Brasil. S.P.

Mantoan, M.T. E. (2006). Inclusão Escolar: O Que E? Por Que? Como fazer? 2. ed. São Paulo, Brasil: Moderna.

Marcondes, M.A.S. (2005).Educação Comparada: perspectivas teóricas e investigações. Eccos- $R e-$ vista cientifica, Universidade Nove de Julho, São Paulo, Brasil. 
Minayo, M.C. (Org.). (2009). Pesquisa social: teoria, método e criatividade. - 28. ed. - Petrópolis.: Vozes.

Nascimento, P. R; Cristovão, L.L. Nilce. (2018). Prática de Ensino e Formação de Professores para Educação Básica em uma perspectiva Inclusiva. Educação e Tecnologias educação em cenários em transição, CIETEnPED. UFSCar.

Nogueira, F.M.; Chemello, J. dos S.; Borges, T.O.S. (2018). Atividade Pedagógica Inclusiva: aprendendo com os animais. Universidade Cruzeiro do Sul, São Paulo, Brasil.SP.

Oliveira, F. N. Cristovão, N. L. L.; Nascimento, R. P. Bispo, J. B. (2018).Projeto Interdisciplinar: Horta comunitária inclusiva. Universidade Cruzeiro do Sul. São Paulo, Brasil. SP.

Oliveira, F. M. e Alencar, E. S. (2019) Literatura infantil como recurso metodológico para o ensino da matemática inclusiva Science and Knowledge in Focus 1(2), 21-35

Ostetto, L.E. (2000). Encontros e encantamentos na educação infantil. Campinas. São Paulo, Brasil: Papirus.

Omote, S. (2004). Inclusão: da intenção à realidade. In: OMOTE, S. (Org.). Inclusão: intenção e realidade. Marília: Fundepe.

Pimenta, S. G., Garrido, E., Moura, M.O. (2000). Pesquisa colaborativa na escola como abordagem facilitadora para o desenvolvimento da profissão de professor. In: Marin, Alda A. J(Org.). Educação continuada. Campinas: Papirus.

Santos, É. G. S., A.T, da S.; Andrade, A.M., Cristovão, N.L.L.(2018).Matemática interdisciplinar a Educação Inclusiva. Universidade Cruzeiro do Sul. São Paulo, Brasil SP.

Saraiva, J.A.(2001). Literatura e alfabetização: do plano do choro ao plano da ação. Porto Alegre, Brasil: Artes Médicas.

Schlunzen, E.T.M., Santos, D.A. do N. (2016). Práticas Pedagógicas do Professor: abordagem construcionista, contextualizada e significativa para uma educação inclusiva. Curitiba, Brasil: Appris,.

Semetko, H.A., Scammell, M. (2012). O SAGE handbook political communication. London: SAGE.

Silva, T.P.; Barros, R. A. (2018) Uma proposta de sequência didática para o ensino de Matemática nos anos iniciais do Ensino Fundamental. In: Anais do XVIII Encontro de Educação Matemática. Campus Cora Coralina/UEG, Goiás.

Schmidt, C. (2013). Autismo, educação e transdisciplinaridade. Campinas: Papirus.

Smole,K. S. (1996).Era uma vez na Matemática: uma conexão com a literatura infantil. $3^{a}$ ed. São Paulo, Brasil: IME/USP-CAEM.

Sousa, D. L., Cristovão, N.L.L. (2018). Máquina de Reciclagem. Universidade Cruzeiro do Sul. São Paulo, Brasil. S.P.

Vigostsky,L.S.(1989). Linguagem e pensamento. São Paulo, Brasil: Martins Fontes. 